\title{
Combined photolysis and catalytic ozonation of dimethyl phthalate in a high-gravity rotating packed bed
}

\author{
Chia-Chi Chang a , Chun-Yu Chiu ${ }^{\mathrm{b}}$, Ching-Yuan Chang ${ }^{\mathrm{a}, *}$, Chiung-Fen Chang ${ }^{\mathrm{c}}$, \\ Yi-Hung Chen ${ }^{\mathrm{d}}$, Dar-Ren Ji ${ }^{\mathrm{a}}$, Yue-Hwa $\mathrm{Yu}^{\mathrm{a}}$, Pen-Chi Chiang ${ }^{\mathrm{a}}$ \\ a Graduate Institute of Environmental Engineering, National Taiwan University, Taipei 106, Taiwan \\ ${ }^{\mathrm{b}}$ Department of Cosmetic Science and Application, Lan-Yang Institute of Technology, I-Lan 261, Taiwan \\ ${ }^{c}$ Department of Environmental Science and Engineering, Tunghai University, Taichung 407, Taiwan \\ d Department of Chemical and Material Engineering, National Kaohsiung University of Applied Science, Kaohsiung City 807, Taiwan
}

\section{A R T I C L E I N F O}

\section{Article history:}

Received 4 January 2008

Received in revised form 19 March 2008

Accepted 19 March 2008

Available online 26 March 2008

\section{Keywords:}

Ozonation

High-gravity rotating packed bed (HGRPB)

Photolysis

Dimethyl phthalate (DMP)

Catalyst

\begin{abstract}
A B S T R A C T
In this study, a high-gravity rotating packed bed (HGRPB) was used as a catalytic ozonation reactor to decompose dimethyl phthalate (DMP), an endocrine disrupting chemical commonly encountered. The HGRPB is an effective gas-liquid mixing equipment which can enhance the ozone mass transfer coefficient. Platinum-containing catalyst $\left(\mathrm{Pt} /-\mathrm{Al}_{2} \mathrm{O}_{3}\right)$ of Dash $220 \mathrm{~N}$ and ultra violet (UV) lamp were combined in the high-gravity ozonation (HG-OZ) system to enhance the self-decomposition of molecular ozone in liquid to form highly reactive radical species. Different combinations of $\mathrm{HG}-\mathrm{OZ}$ with Dash $220 \mathrm{~N}$ and UV for the degradation of DMP were tested. These include HG-OZ, HG catalytic OZ (HG-Pt-OZ), HG photolysis OZ (HG-UV-OZ) and HG-UV-Pt-OZ. The result indicated that all the above four ozonation processes result in significant decomposition of DMP and mineralization of total organic carbon (TOC) at the applied ozone dosage per volume of liquid sample of $1.2 \mathrm{~g} \mathrm{~L}^{-1}$. The $\mathrm{UV}$ and $\mathrm{Pt} / \gamma-\mathrm{Al}_{2} \mathrm{O}_{3}$ combined in HG-OZ can enhance the TOC mineralization efficiency ( $\eta_{\text {TOC }}$ ) to 56\% (via HG-UV-OZ) and $57 \%$ (via HG-Pt$\mathrm{OZ}$ ), respectively, while only $45 \%$ with ozone only. The process of HG-UV-Pt-OZ offers the highest $\eta_{\text {TOC }}$ of about $68 \%$.
\end{abstract}

(c) 2008 Elsevier B.V. All rights reserved.

\section{Introduction}

Endocrine disrupting chemicals (EDCs, also called environmental hormones) have been spread over the environment and influenced the generative function of some species on the earth. Most of EDCs are persistent organic pollutants (POPs) which exhibit chronic toxicity, bioaccumulation and are difficult to be decomposed by organisms in the environment. Among the EDCs, phthalate acid esters (PAEs) are chemical compounds most widely used in the plastic industrial production. The major applications of PAEs are for the use as plasticizers for polyvinyl chloride (PVC) resins, adhesives and cellulose film coating (counting about $85 \%$ of the whole production). The short-chained ester such as dimethyl phthalate (DMP) is among the most frequently identified PAEs in diversified environmental samples including upper layer of marine water, surface waters and sediments. Esters are found to accumulate in the environment and to be toxic to a variety of aquatic organisms, which are at the base of the food chain in both marine and sur-

\footnotetext{
* Corresponding author. Tel.: +88622363 8994; fax: +88622363 8994 .

E-mail address: cychang3@ntu.edu.tw (C.-Y. Chang).
}

face water environments. Destruction of these compounds requires the application of processes having high decomposition abilities such as those being able to provide highly reactive hydroxyl radicals. Recently, researches showed that phthalate esters in secondary effluent and surface water can be decomposed via $\mathrm{O}_{3} / \mathrm{UV}$ processes $[1,2]$.

Ozonation processes have been widely applied to water and wastewater treatment. In aqueous solution, ozone acts on various compounds by direct ozonation and radical reaction. Molecular ozone is a powerful oxidant agent which reacts selectively with organic compounds in water. The organic compounds with molecular structure consisting of multiple bonds (for example $\mathrm{C}=\mathrm{C}$, $\mathrm{C}=\mathrm{C}-\mathrm{O}-\mathrm{R}$ and $-\mathrm{C}=\mathrm{C}-\mathrm{X}$ ) or atom carrying a negative charge (such as $\mathrm{N}, \mathrm{P}, \mathrm{O}, \mathrm{S}$ and nucleophilic carbon) are highly reactive with ozone [3]. The ozonation system should be able to form highly reactive radical species from the decomposition of molecular ozone in water so as to destruct the POPs via free radical chain reaction. Alternative ozonation processes using catalysts of transition metals also have been applied for the degradation of organics. Catalytic ozonation can be classified according to (1) activation of ozone via metal ions in solution and (2) heterogeneous catalytic ozonation in the presence of metal oxides or metals on supports [4]. The use of metal 


\begin{tabular}{|c|c|}
\hline \multicolumn{2}{|c|}{ Nomenclature } \\
\hline$a$ & $\begin{array}{l}\text { specific area of gas-liquid interface per unit volume } \\
\text { of contactor or packed bed }\left(\mathrm{m}^{2} \mathrm{~m}^{-3}\right)\end{array}$ \\
\hline AOPs & advanced oxidation processes \\
\hline BET & Brunauer-Emmett-Teller surface adsorption \\
\hline C & concentration of DMP $\left(\mathrm{mg} \mathrm{L}^{-1}\right)$ \\
\hline$C_{0}$ & initial concentration of DMP $\left(\mathrm{mg} \mathrm{L}^{-1}\right)$ \\
\hline$C_{\mathrm{AG}, \text { in }}$ & concentration of feed $\mathrm{O}_{3}\left(\mathrm{mg} \mathrm{L}^{-1}\right)$ \\
\hline CSTR & completely stirred tank reactor \\
\hline DMP & dimethyl phthalate \\
\hline EDC & endocrine disrupting chemical \\
\hline HGRPB & high-gravity rotating packed bed \\
\hline $\mathrm{HG}-\mathrm{OZ}$ & HGRPB-ozonation \\
\hline \multicolumn{2}{|c|}{ HG-Pt-OZ Pt catalytic HG-OZ } \\
\hline \multicolumn{2}{|c|}{ HG-UV-OZ ultra violet $\mathrm{HG}-\mathrm{OZ}$} \\
\hline \multicolumn{2}{|c|}{ HG-UV-Pt-OZ Pt catalytic HG-UV-OZ } \\
\hline HRT & hydraulic retention time $(\mathrm{s})$ \\
\hline$k_{\mathrm{LA}}^{0}$ & $\begin{array}{l}\text { physical liquid-phase mass transfer coefficient of } \\
\text { ozone }\left(\mathrm{m} \mathrm{s}^{-1}\right)\end{array}$ \\
\hline$m_{\mathrm{A}, \mathrm{in}}$ & $\begin{array}{l}\text { applied dosage of ozone per volume of liquid sample } \\
\left(\mathrm{mg} \mathrm{L}^{-1}\right)\end{array}$ \\
\hline$m_{\mathrm{S}}$ & mass of catalyst $(\mathrm{g})$ \\
\hline$N_{\mathrm{r}}$ & rotating speed of HGRPB (rpm) \\
\hline PAEs & phthalate acid esters \\
\hline POPs & persistent organic pollutants \\
\hline & flow rate of feed $\mathrm{O}_{3}\left(\mathrm{~L} \mathrm{~min}^{-1}\right)$ \\
\hline$Q_{\mathrm{LR}}$ & flow rate of recycled liquid $\left(\mathrm{L} \mathrm{min}^{-1}\right)$ \\
\hline RB5 & Reactive black 5 \\
\hline RB19 & Reactive blue 19 \\
\hline$t$ & reaction time $(\mathrm{min})$ \\
\hline$T$ & temperature $\left({ }^{\circ} \mathrm{C}\right)$ \\
\hline TOC & total organic carbon \\
\hline UV & ultra violet \\
\hline$V_{\mathrm{L}}$ & sample volume (L) \\
\hline \multicolumn{2}{|c|}{ Greek letters } \\
\hline$\varepsilon_{\mathrm{B}}$ & void fraction of packed bed \\
\hline$\eta_{\text {TOC }}$ & mineralization efficiency of TOC \\
\hline
\end{tabular}

ions as the homogeneous catalyst has no mass transfer resistance between the reactants and catalyst. However, the metal ion remains in the solution and is not easy to be recovered or removed. Solid catalysts which are packed in the packed bed are able to be recycled and regenerated. The catalysts with metals such as $\mathrm{Pt}, \mathrm{Ru}, \mathrm{Rh}, \mathrm{Pd}$ and $\mathrm{Ag}$ were reported to be effective for the decomposition of organic compounds in gaseous as well as aqueous-phase ozonation. The order of catalytic activity of metals supported on $\mathrm{Al}_{2} \mathrm{O}_{3}$ was found to be: $\mathrm{Pt}>\mathrm{Pd}>\mathrm{Ag}>\mathrm{Ru} \sim \mathrm{Rh} \sim \mathrm{Ir}>\mathrm{Ni}>\mathrm{Cd}>\mathrm{Mn}>\mathrm{Fe}>\mathrm{Cu}>\mathrm{Zn} \sim \mathrm{Zr}[5]$. In this study, platinum-containing catalyst, Dash $220 \mathrm{~N}$, was chosen as the catalyst to produce the hydroxyl radicals from aqueous ozone.

Ozonation is limited by its selective reactivity and low gas-liquid mass transfer rate. The high-gravity rotating packed bed (HGRPB, HG or Higee) was used in this study as a gas-liquid contactor to enhance the mass transfer rate between the phases. The values of volumetric gas-liquid mass transfer coefficients achievable in HGRPB are one or two orders of magnitude higher than those in conventional packed beds [6]. Recent studies [7-9] showed that HGRPB has some advantageous characteristics such as (1) fast renewable rate on the surface of packed materials, (2) high gas-liquid mass transfer coefficients, (3) short time to reach steady state, (4) low overflow rate, (5) short hydraulic retention time (HRT) and (6) thin liquid film.
HGRPB is also applicable to absorption, adsorption, desorption, distillation, polymer devolatilization, bio-oxidation, reactive crystallization, stripping, extraction and other separation processes [10]. Recently, HGRPB also has been used for micro-mixing and emulsion [11,12].

Previous studies point out that HGRPB has a higher mass transfer rate in gas-liquid system than conventional gas-liquid contactor. Thus, the ozonation process can be combined with HGRPB to enhance the ozone mass transfer from gas phase to liquid phase. Lin and Liu [13] found that the centrifugal force can facilitate the decolorization efficiency of dyestuff Reactive Blue 19 (RB19) because the mass transfer rate of ozone is enhanced via increasing the interfacial area and decreasing the resistance of ozone transfer. Chen et al. [14] used RPB as well as completely stirred tank reactor (CSTR) as ozone gas-liquid contactor to treat CI Reactive Black 5 (RB5). The results indicated that the mass transfer coefficient of RPB $\left(k_{\mathrm{LA}}^{0} a=0.0975 \mathrm{~s}^{-1}\right)$ is significantly higher than that of CSTR $\left(k_{\mathrm{LA}}^{0} a=0.0248 \mathrm{~s}^{-1}\right)$.

In this research, the HGRPB was applied to the catalytic ozonation processes using $\mathrm{Pt} / \gamma-\mathrm{Al}_{2} \mathrm{O}_{3}$ to decompose the organic compound of DMP in aqueous solution. System performances for the degradation of DMP via various advanced oxidation processes (AOPs) using HGRPB were examined and compared. These HGRPB assisted AOPs include HGRPB-ozonation (HG-OZ), Pt catalytic HG$\mathrm{OZ}$ (HG-Pt-OZ), ultra violet HG-OZ (HG-UV-OZ) and HG-UV-Pt-OZ. The results can provide insight information for the feasibility evaluation of applying a HGRPB to the said AOPs.

\section{Experimental}

\subsection{Chemicals}

DMP with chemical formula of $\mathrm{C}_{10} \mathrm{H}_{10} \mathrm{O}_{4}$, molecular weight of 194.19 and purity $>99 \%$ was purchased from Hayashi Pure Chemical Industries Ltd. (Osaka, Japan). The water solubility of DMP is $4000 \mathrm{mg} \mathrm{L}^{-1}$ at $25^{\circ} \mathrm{C}$ ( $\left.1 \mathrm{~atm}\right)$. The DMP was subjected to DI water prior to the use with the concentration $\left(C_{\mathrm{DMP}}\right)$ of $100 \mathrm{mg} \mathrm{L}^{-1}$. The initial $\mathrm{pH}$ of the DMP solution is about 7.5. The potassium iodine $(\mathrm{KI})$, sodium chloride $(\mathrm{NaCl})$ and acetonitrile $\left(\mathrm{CH}_{3} \mathrm{CN}\right)$ used were of analytical grade (J.T. Baker, Phillipsburg, NJ, USA). Ozone was decomposed to form radicals via a commercial $\mathrm{Pt} / \gamma-\mathrm{Al}_{2} \mathrm{O}_{3}$ catalyst Dash 220 N (N.E. Chemical Co., Japan), which is a platinumcontaining catalyst. Characteristic of the Dash $220 \mathrm{~N}$ is shown in Table 1 [15]. Dash $220 \mathrm{~N}$ is a spherical catalyst $3-4 \mathrm{~mm}$ in diameter. The bulk density of the Dash $220 \mathrm{~N}$ is $0.77 \mathrm{~g} \mathrm{~cm}^{-3}$. The content of platinum in the alumina sphere is about $0.23 \mathrm{wt} . \%$.

\subsection{Instrumentation}

The HGRPB system (Fig. 1) was carried out via semi-batch operation. The system has two major parts, namely RPB and photoreactor. The RPB consists of a packing chamber, a rotor and a stationary housing. The DMP solution flows outward from the inner edge of

Table 1

Characterization of $\mathrm{Pt} / \gamma-\mathrm{Al}_{2} \mathrm{O}_{3}$ DASH $220 \mathrm{~N}$ catalyst [13]

\begin{tabular}{ll}
\hline Average particle diameter, $d_{\mathrm{P}}$ & $4 \mathrm{~mm}$ \\
Total BET surface area, $A_{\mathrm{B}}$ & $166.62 \mathrm{~m}^{2} \mathrm{~g}^{-1}$ \\
Total pore volume, $V_{\mathrm{t}}$ & $0.4392 \mathrm{~cm}^{3} \mathrm{~g}^{-1}$ \\
Average pore diameter, $d_{\mathrm{Pr}}$ & $76 \AA$ \\
Bulk particle density, $\rho_{\mathrm{P}}$ & $0.77 \mathrm{~g} \mathrm{~cm}^{-3}$ \\
Ture density, $\rho_{\mathrm{s}}$ (He displacement method) & $3.22 \mathrm{~g} \mathrm{~cm}^{-3}$ \\
Porosity, $\varepsilon_{\mathrm{P}}$ & 0.59 \\
Pt content in catalyst & $0.23 \mathrm{wt} . \%$ \\
\hline
\end{tabular}

BET: Brunauer-Emmett-Teller surface adsorption. 


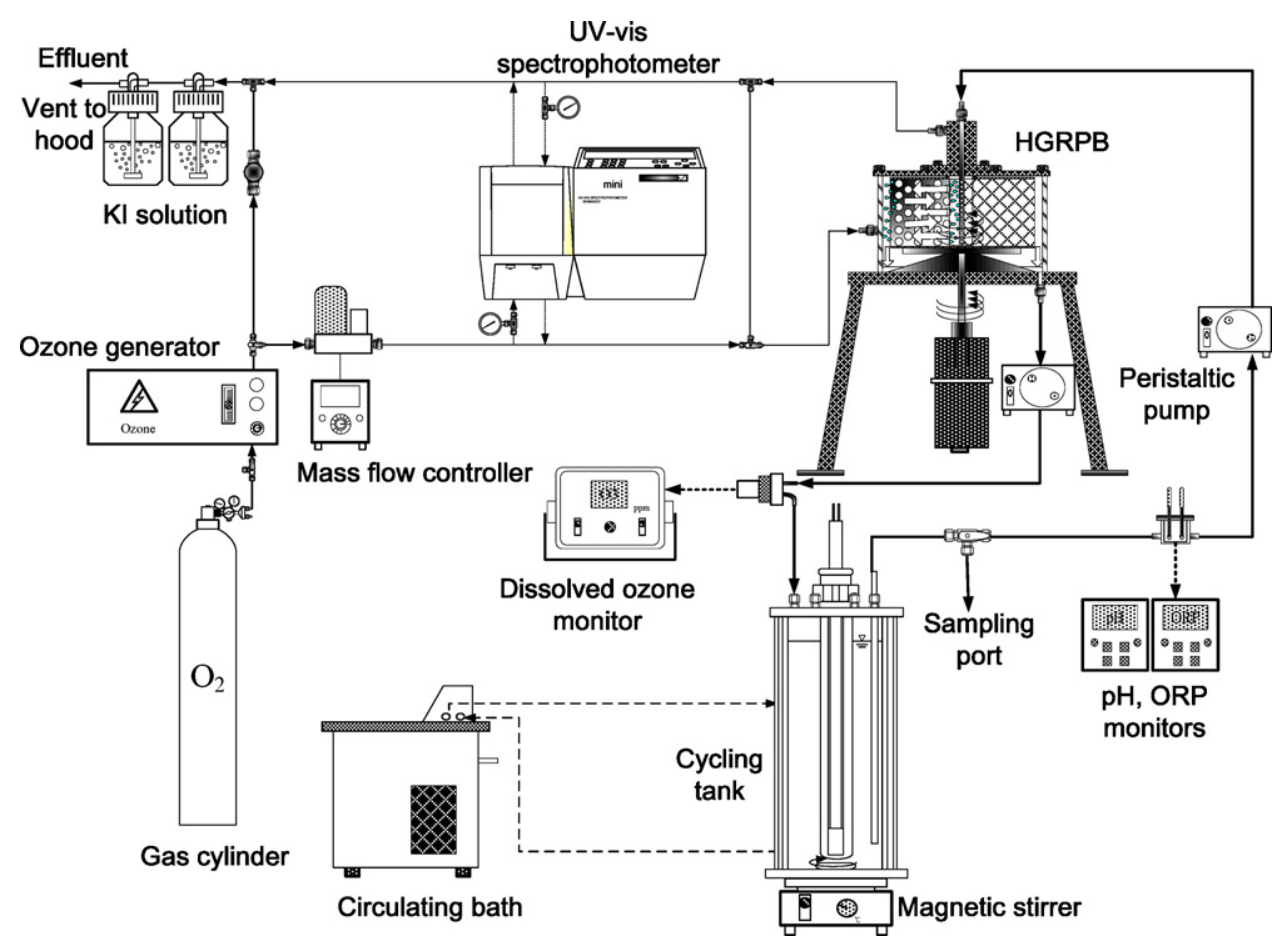

Fig. 1. Schematic diagram of HGRPB system.

the packing chamber subjected to the centrifugal force. Gaseous ozone flows inward countercurrently from the outer edge of the packed bed by the pressure-driving force. The experiments were performed with the volume $\left(V_{\mathrm{L}}\right)$ of DMP solution of $1 \mathrm{~L}$ and total reaction time $(t)$ of $60 \mathrm{~min}$. To identify the catalytic ability of platinum in ozonation system, two packing materials of Dash $220 \mathrm{~N}$ and spherical glass beads were used and tested in the packed bed. The diameter of glass beads is about the same as that of Dash $220 \mathrm{~N}$. The RPB is $2 \mathrm{~cm}$ in height and $5.9 \mathrm{~cm}$ in diameter. In the experiments, the RPB was operated with rotating speed $\left(N_{\mathrm{r}}\right)$ from 600 to $1800 \mathrm{rpm}$, which provided gravitational force of $23.76-213.91 \mathrm{~g}$ (232.92-2096.31 $\mathrm{m} \mathrm{s}^{-2}$ ). The DMP solution was fed to RPB by a peristaltic pump at $462 \mathrm{~mL} \mathrm{~min}^{-1}$ recycle rate $\left(Q_{\mathrm{LR}}\right)$ and contacted with gaseous ozone and catalysts in the bed.

The photoreactor is made of Pyrex glass with the dimensions of diameter and height of 5 and $30 \mathrm{~cm}$, respectively. A UV lamp (TUV-16W, Phillps, Tokyo, Japan) was placed at the center of the UV reactor and shielded by a quartz jacket. The UV irradiation was introduced to enhance the decomposition of ozone to form the $\mathrm{OH}^{\bullet}$ radical. All the experiments were controlled at $25^{\circ} \mathrm{C}$ with water jacket around the reactor. The DMP solution was pumped and recycled continuously through a closed loop connected with all sensors of $\mathrm{pH}$, oxidation reduction potential (ORP) and dissolved ozone $\left(\mathrm{DO}_{3}\right)$ monitors. Liquid samples were taken from a sampling port for chemical analyses.

The ozone was generated from dried oxygen with purity of 99.99\% via corona discharge using an ozone generator (Model LAB2B, Ozonia, Duebendorf, Switzerland). The ozone inlet flow rate $\left(Q_{G}\right)$ was controlled via a mass flow controller (MFC, Model 5850E, Brooks, Hatfield, PA, USA) at $1 \mathrm{~L} \mathrm{~min}^{-1}$. The inlet and outlet gaseous ozone concentrations were measured via a spectrophotometer (UV mini-1240, Shimadzu, Kyoto, Japan) with the absorbance of ozone measured in a $2 \mathrm{~mm}$ flow-through quartz cell at the wavelength $258 \mathrm{~nm}$. An extinction coefficient of $3000 \mathrm{M}^{-1} \mathrm{~s}^{-1}$ was used to convert absorbances into concentration units [16]. The inlet ozone concentration $\left(C_{\mathrm{AG}, \text { in }}\right)$ was controlled at $25 \mathrm{mg} \mathrm{L}^{-1}$. Ozone concentration in water was determined by $\mathrm{DO}_{3}$ meter (Model 3600 , Orbisphere, Trasadingen, Switzerland). The UV-vis irradiation intensity was measured by diffraction grating spectrometer (Model EPP 2000, StellarNet, Oldsmar, FL, USA).

The analyses of DMP solutions were performed using the high performance liquid chromatography (HPLC, Model 500, Viscotek, Houston, TX, USA) with $250 \mathrm{~mm} \times 4.6 \mathrm{~mm}$ C18 column (LC-18, Supelco, Bellefonte, PA, USA) to separate the DMP and by-products of ozonation. The wavelength of UV/visible detector (Model 1706, Bio-Rad, Hercules, CA, USA) was set at $220 \mathrm{~nm}$. Effluent is composed of $\mathrm{CH}_{3} \mathrm{CN}$ and DI water $\left(\mathrm{CH}_{3} \mathrm{CN} / \mathrm{DI}\right.$ water $\left.=50 / 50\right)$ with flow rate controlled at $1.0 \mathrm{~mL} \mathrm{~min}^{-1}$. Total organic carbon (TOC) was analyzed by TOC analyzer (Model 1010, O.I. analytical, College Station, TX, USA).

\section{Results and discussion}

\subsection{Hydraulic test}

Heterogeneous catalytic ozonation of DMP in HGRPB is a gas-liquid-solid reaction for which mass transfer and chemical reaction may play important roles. The mass transfer is dependent on the mixing of liquid, gaseous ozone and solid catalyst. The HGRPB is an efficient mixing apparatus with its high rotating speed. The HRT of HGRPB was determined by observing the variation of conductivity of tracer-containing effluent. The tracer $(\mathrm{NaCl})$ was injected in the influent in the entrance of HGRPB. Fig. 2 shows the variations of HRT with $N_{\mathrm{r}}$ and $Q_{\mathrm{LR}}$. At low water feeding rate $\left(Q_{\mathrm{LR}}=188 \mathrm{~mL} \mathrm{~min}^{-1}\right)$ and low rotating speed $\left(N_{\mathrm{r}}=300 \mathrm{rpm}\right)$, the HRT was about $10 \mathrm{~s}$. The HRT reduced to $8 \mathrm{~s}$ as $N_{\mathrm{r}}$ increased to $600 \mathrm{rpm}$ for the case with $Q_{\mathrm{LR}}=188 \mathrm{~mL} \mathrm{~min}^{-1}$. At the same $Q_{\mathrm{LR}}$, the HRTs were about the same for the cases with $N_{\mathrm{r}}$ in the range of 600 to $1800 \mathrm{rpm}$. The HRTs were about 8, 6, 5, 4 and 4 at $Q_{L R}$ of $188,463,545,750$ and $857 \mathrm{~mL} \mathrm{~min}^{-1}$. The result showed that at the same $N_{\mathrm{r}}$, the HRT was strongly dependent on $Q_{\mathrm{LR}}$. High $N_{\mathrm{r}}$ leads to high centrifugal force assisting the fluid spraying outward 

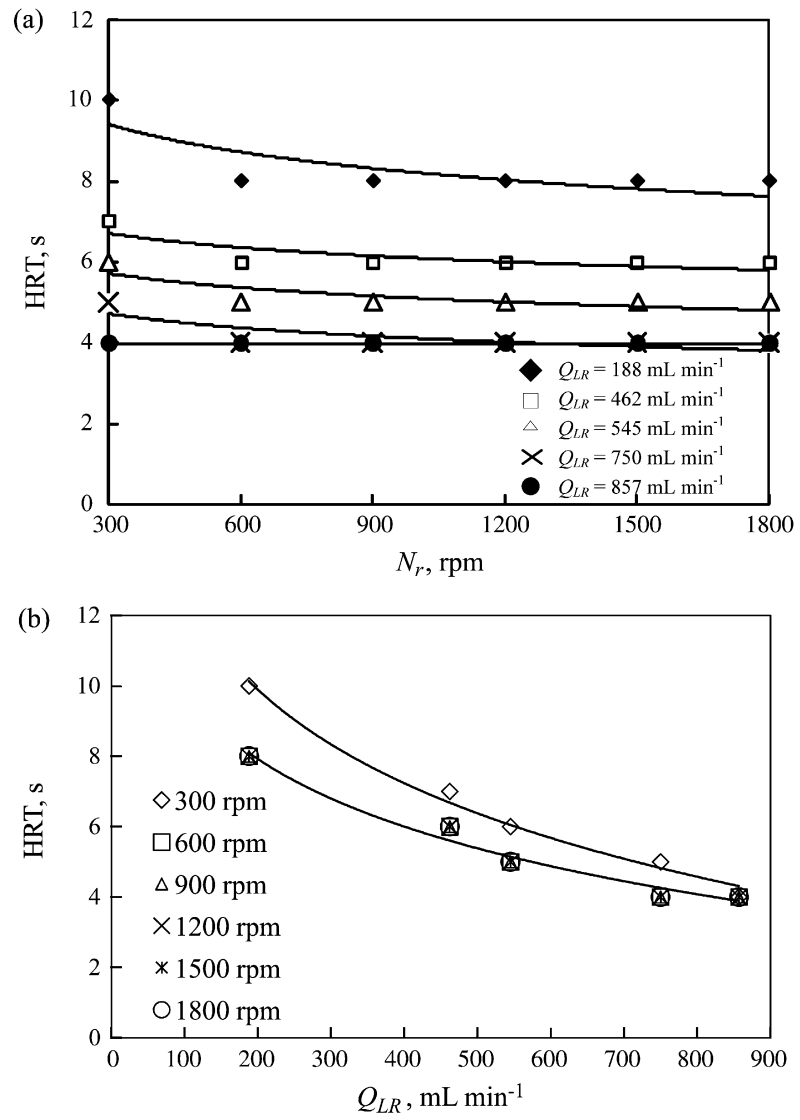

Fig. 2. (a) Hydrolytic retention time (HRT) vs. rotating speed $\left(N_{\mathrm{r}}\right)$, (b) HRT vs. liquid flow rate $\left(Q_{\mathrm{LR}}\right)$.

through the packed bed. Liquid volume in HGRPB is limited by the voidage of the packed bed $\left(\varepsilon_{\mathrm{B}}\right)$. The total volume of the packed bed is $213.88 \mathrm{~cm}^{3}$ with the volume of packed catalyst of $72.05 \mathrm{~cm}^{3}$ and stainless wire of $18.27 \mathrm{~cm}^{3}$. This gives the free space of the packed bed of $123.56 \mathrm{~cm}^{3}$. Thus, the $\varepsilon_{\mathrm{B}}$ of HGRPB in this experiment was $57.77 \%$. Theoretically, the HRTs without rotating would be $40,16,14$, 10 and $9 \mathrm{~s}$ with $Q_{\mathrm{LR}}$ of $188,462,545,750$ and $875 \mathrm{~mL} \mathrm{~min}^{-1}$. Under high $N_{\mathrm{r}}$, the liquid is speeded up via the centrifugal force, resulting in a significant decrease of HRT down to 4-10 s. However, the high $N_{\text {r }}$ of HGRPB can well mix the liquid with gaseous oxidant in a short time.

\subsection{Photolysis and ozonation of DMP}

The decomposition of DMP in HGRPB systems of HG, HG-UV, HG-OZ and HG-UV-OZ at $Q_{\mathrm{G}}=1 \mathrm{~L} \mathrm{~min}^{-1}, Q_{\mathrm{LR}}=100 \mathrm{~mL} \mathrm{~min}^{-1}$ and $N_{\mathrm{r}}=1200 \mathrm{rpm}$ is shown in Fig. 3. In this part of experiment, the HGRPB was packed with glass spheres $4 \mathrm{~mm}$ in diameter. For the cases without ozone, nitrogen gas was introduced to maintain the same hydraulic conditions. DMP was not decomposed using HG and HG-UV. For the ozonation, the applied ozone dosage $\left(m_{\mathrm{A}, \mathrm{in}}\right)$ and decomposition efficiency of DMP $\left(\eta_{\text {DMP }}\right)$ are defined as follows:

$m_{\mathrm{A}, \text { in }}=Q_{\mathrm{G}} \times C_{\mathrm{AG}, \text { in }} \times t \times V_{\mathrm{L}}^{-1}$

$\eta_{\mathrm{DMP}}=\frac{\left(C_{\mathrm{DMPO}}-C_{\mathrm{DMP}}\right)}{C_{\mathrm{DMPO}}}$

where $Q_{G}, C_{A G, i n}$ and $V_{\mathrm{L}}$ are gas flow rate, concentration of inlet ozone and volume of liquid sample, while $C_{\mathrm{DMPO}}$ (or $C_{0}$ ) and $C_{\mathrm{DMP}}$ ( or $C$ ) are concentrations of DMP at time $t=0$ and $t$, respectively.

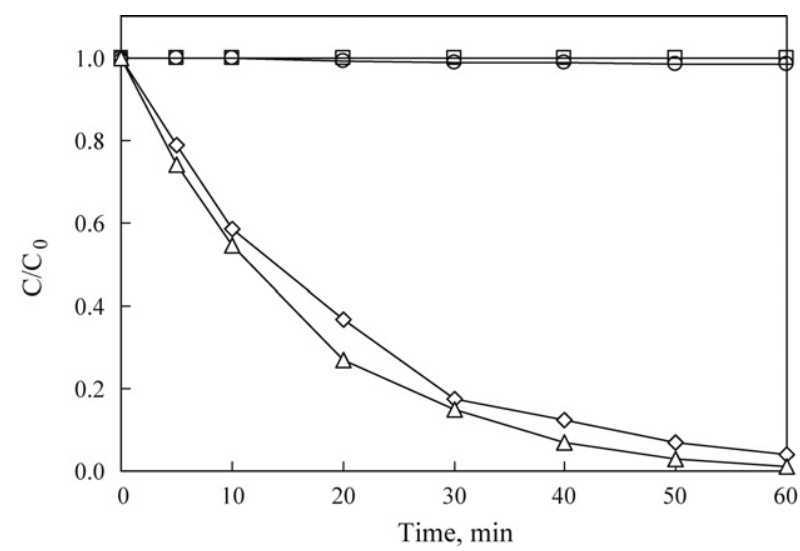

Fig. 3. Time variations of $C / C_{0}$ for the decomposition of DMP in HGRPB systems. Initial concentration of DMP $\left(C_{\mathrm{DMPO}}\right.$ or $\left.C_{0}\right)=100 \mathrm{mg} \mathrm{L}^{-1}, \mathrm{Q}_{\mathrm{G}}=1 \mathrm{~L} \mathrm{~min}^{-1}$ $Q_{\mathrm{LR}}=462 \mathrm{mLmin}^{-1}$, power of UV lamp $=16 \mathrm{~W}$ as noted in specification, $V_{\mathrm{L}}=1 \mathrm{~L}$, $N_{\mathrm{r}}=1200 \mathrm{rpm}, C_{\mathrm{AG}, \text { in }}=20 \mathrm{mg} \mathrm{L}^{-1}, T=25^{\circ} \mathrm{C}$. ( $\left.\square\right)$ : HG only; $(\bigcirc)$ : HG-photolysis (HGUV); $(\diamond)$ : HG ozonation (HG-OZ); $(\Delta)$ : HG-UV-OZ. HGRPB: high-gravity rotating packed bed.

The values of $\eta_{\text {DMP }}$ for $\mathrm{HG}-\mathrm{OZ}$ process reached about $80 \%$ in $30 \mathrm{~min}$ reaction time $\left(m_{\mathrm{A}, \mathrm{in}}=600 \mathrm{mg} \mathrm{L}^{-1}\right)$ and $96 \%$ in $60 \mathrm{~min}$ $\left(m_{\mathrm{A}, \mathrm{in}}=1200 \mathrm{mg} \mathrm{L}^{-1}\right)$, respectively, revealing effective decomposition of DMP via ozonation.

The emission spectrum of UV lamp (denoted as UV raw) for the photolysis experiments is shown in Fig. 4. Fig. 4a shows the

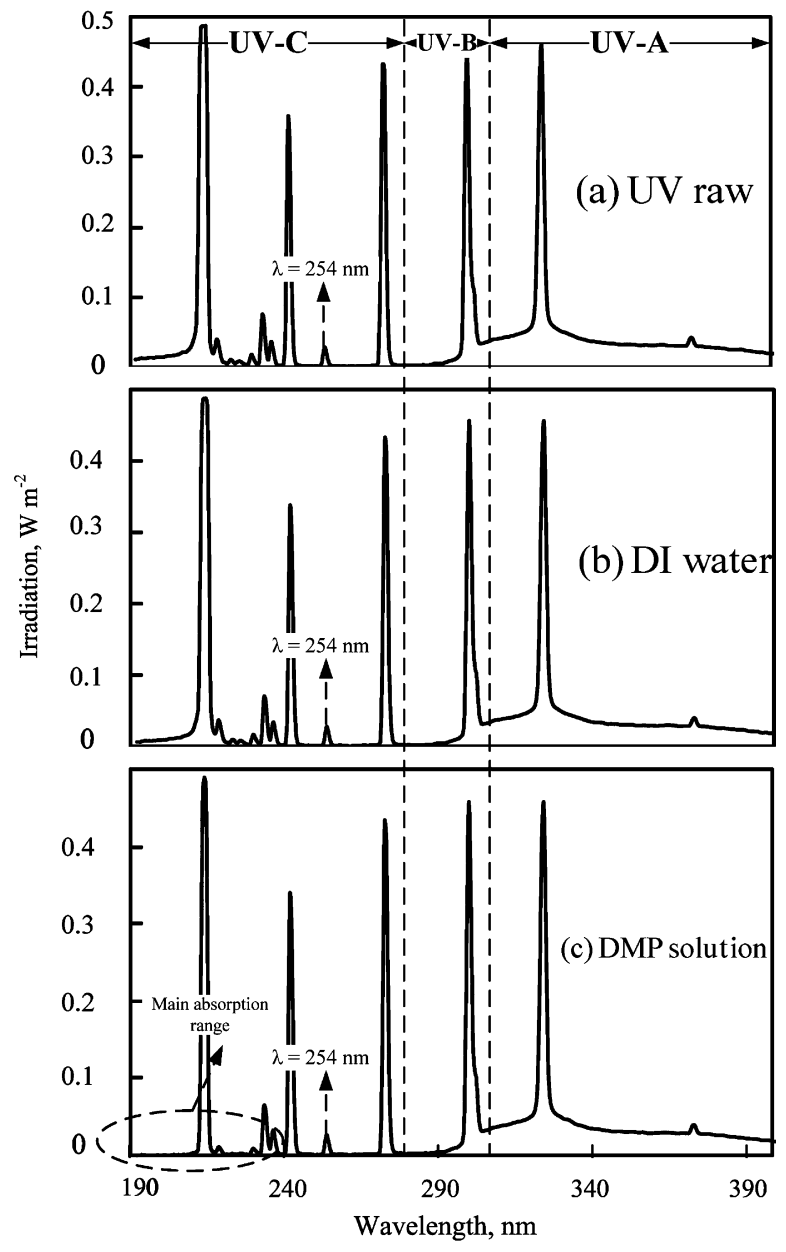

Fig. 4. Absorption spectrum of DMP. Light source: $16 \mathrm{~W}$ UV lamp $C_{\mathrm{DMPO}}=100 \mathrm{mg} \mathrm{L}^{-1}$. 
raw emission spectrum of the UV lamp. It indicated that the lowpressure UV lamp employed is a multi-wavelengths light source with three regions of UV-A, UV-B and UV-C. The irradiation intensities of the UV lamp in UV-A (315-400 nm), UV-B (280-315 nm) and UV-C (200-280 $\mathrm{nm})$ are $3.99,1.59$ and $3.73 \mathrm{~W} \mathrm{~m}^{-2}$ counting the whole wavelength range of the respective regions. Fig. $4 \mathrm{~b}$ and $\mathrm{c}$ are UV spectrum through DI water and DMP solution. The DMP has obvious UV absorption below $240 \mathrm{~nm}$, while ozone absorbs UV light of short wavelengths in 200-300 nm with the maximum absorption coefficient at $253.7 \mathrm{~nm}$. As shown in Fig. $4 \mathrm{a}$ and c, the UV lamp energy emitted was absorbed by DMP solution in UV-C region, while there was no absorption in UV-A and UV-B regions.

The results of Fig. 3 for the photolysis of DMP were obtained using the low-pressure UV lamp, yielding $\eta_{\text {DMP }}$ of $2 \%$. The corresponding removal efficiency (or mineralization efficiency) of TOC $\left(\eta_{\mathrm{TOC}}=\left(C_{\mathrm{TOC} 0}-C_{\mathrm{TOC}}\right) / C_{\mathrm{TOC} 0}\right)$ was relatively low. Thus, DMP is hard to be destructed via UV irradiation only. As UV irradiation was combined with HG-OZ system (HG-UV-OZ process), the decomposition of DMP reached $85 \%$ in $30 \mathrm{~min}$ reaction time $\left(m_{\mathrm{A}, \mathrm{in}}=600 \mathrm{mg} \mathrm{L}^{-1}\right)$ and $99 \%$ in $60 \mathrm{~min}\left(m_{\mathrm{A}, \text { in }}=1200 \mathrm{mg} \mathrm{L}^{-1}\right)$.

In UV-OZ process for the decomposition of DMP, molecules absorbing UV irradiation of UV-C region include:

(1) molecular ozone - enhancing the decomposition of ozone in water and generating highly reactive hydroxyl radicals,

(2) DMP molecule - absorbing UV-C via the aromatic ring,

(3) intermediates from the decomposition of DMP - absorbing UV and reacting with ozone and hydroxyl radicals to yield other by-products (such as phenols-quinines-aromatic acids, shortchain aliphatic acids and short-chain aliphatic aldehydes).

The mechanism of UV-OZ may be described as follows. In aqueous phase, the dissolved ozone absorbs UV radiation to product hydrogen peroxide $\left(\mathrm{H}_{2} \mathrm{O}_{2}\right)$ via the following reactions [17]:

$\mathrm{O}_{3}+\mathrm{H}_{2} \mathrm{O} \stackrel{h v}{\longrightarrow} \mathrm{O}_{2}+\mathrm{H}_{2} \mathrm{O}_{2}$

$\mathrm{O}_{3}+\mathrm{H}_{2} \mathrm{O} \stackrel{h v}{\longrightarrow} \mathrm{O}_{2}+2 \mathrm{OH}^{\bullet}$

The second step of UV-OZ process is to form hydroxyl radical. The $\mathrm{H}_{2} \mathrm{O}_{2}$ may be decomposed further to form hydroxyl radical via photolysis or ozonation as follows.

Photolysis:

$\mathrm{H}_{2} \mathrm{O}_{2} \stackrel{h v}{\longrightarrow} 2 \mathrm{OH}^{\bullet}$

Ozone enhanced decomposition:

$\mathrm{H}_{2} \mathrm{O}_{2} \leftrightarrow \mathrm{HO}_{2}^{-}+\mathrm{H}^{+}$

$\mathrm{HO}_{2}^{-}+\mathrm{O}_{3} \rightarrow \mathrm{HO}_{2}{ }^{\bullet}+\mathrm{O}_{3}^{\bullet-}$

$\mathrm{O}_{3}{ }^{-}+\mathrm{H}^{+} \rightarrow \mathrm{HO}_{3}{ }^{\bullet} \rightarrow \mathrm{OH}^{\bullet}+\mathrm{O}_{2}$.

Comparing the reactions in the above pathway, the reaction rate of $\mathrm{H}_{2} \mathrm{O}_{2}$ via photolysis is quite slow (Eq. (5)). Therefore, the decomposition of $\mathrm{H}_{2} \mathrm{O}_{2}$ via ozone to form hydroxyl radical is the main pathway (Eqs. (6)-(8)) in this experiment.

The initial $\mathrm{pH}$ value of sample solution was about 7.5. For the HG and HG-UV processes, the $\mathrm{pH}$ values were remained at about 7.5 because of nearly no decomposition of DMP. Nevertheless, the $\mathrm{pH}$ value of DMP solution decreased during the ozonation because of the formation of intermediates such as aromatic acids and shortchain aliphatic acids. In the $\mathrm{HG}-\mathrm{OZ}$ process, the $\mathrm{pH}$ value decreased from 7.5 to 6.0 and 3.6 in 5 and $15 \mathrm{~min}$, respectively. As for the HGUV-OZ process, the $\mathrm{pH}$ value changed from 7.5 to 5.9 and 6.2 in 5

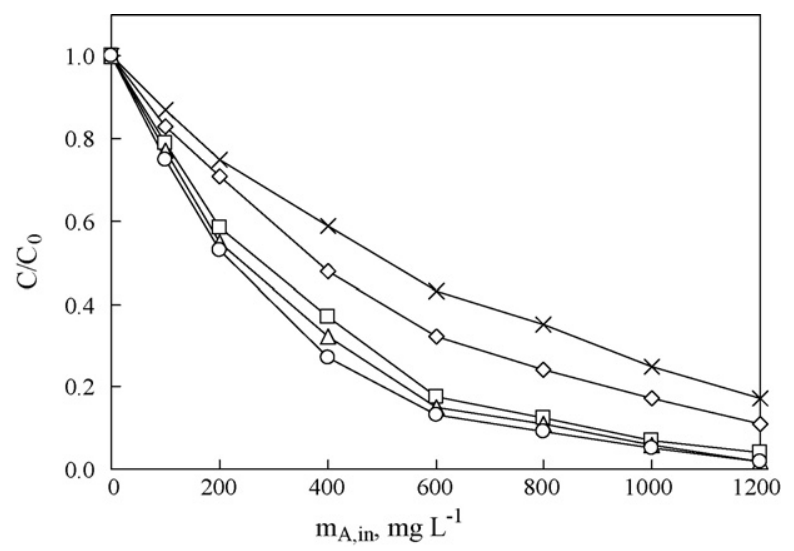

Fig. 5. Effects of $m_{\mathrm{A}, \text { in }}$ on the decomposition of DMP for the HG-OZ process at various $N_{\mathrm{r}}$. $C_{\mathrm{DMPO}}$ (or $\left.C_{0}\right)=100 \mathrm{mg} \mathrm{L}^{-1}, \mathrm{Q}_{\mathrm{G}}=1 \mathrm{~L} \mathrm{~min}^{-1}, Q_{\mathrm{LR}}=462 \mathrm{~mL} \mathrm{~min}^{-1}, V_{\mathrm{L}}=1 \mathrm{~L}$, $C_{\mathrm{AG}, \text { in }}=20 \mathrm{mg} \mathrm{L}^{-1}, T=25^{\circ} \mathrm{C} .(\times),(\diamond),(\square),(\Delta)$ and $(\bigcirc): N_{\mathrm{r}}=600,900,1200,1600$ and $1800 \mathrm{rpm}$

and 15 min, respectively. At later period of HG-UV-OZ, the pH value of solution increased slightly because of further decomposition of organic acids.

\subsection{Effects of $m_{A, i n}$ and $N_{r}$ on the ozonation of DMP}

The decomposition of DMP via the HG-OZ process at various $N_{\mathrm{r}}$ of HGRPB is shown in Fig. 5. The conditions of the process were: $C_{\mathrm{DMP} 0}=100 \mathrm{mg} \mathrm{L}^{-1}, Q_{\mathrm{G}}=1 \mathrm{~L} \mathrm{~min}^{-1}, \mathrm{Q}_{\mathrm{L} R}=462 \mathrm{~mL} \mathrm{~min}^{-1}$, $V_{\mathrm{L}}=1 \mathrm{~L}$ and $C_{\mathrm{AG}, \text { in }}=25 \mathrm{mg} \mathrm{L}^{-1}$. Five rotating speeds $600,900,1200$, 1600 and $1800 \mathrm{rpm}$ were tested to evaluate the effect of $N_{\mathrm{r}}$ on $C / C_{0}$. The corresponding gravitational forces resulted were 23.76 , 53.48, 95.07, 148.55 and $213.91 \mathrm{~g}(232.92,524.08,931.70,1455.77$ and $2096.31 \mathrm{~m} \mathrm{~s}^{-2}$ ), respectively. The result showed that under the experimental conditions, the values of $\eta_{\text {DMP }}$ increase significantly with $N_{\mathrm{r}}$. As $N_{\mathrm{r}}$ increased from 600 to $1800 \mathrm{rpm}$, the $\eta_{\mathrm{DMP}}$ at $m_{\mathrm{AG}, \text { in }}=1200 \mathrm{mg} \mathrm{L}^{-1}$ increased from 83 promote to $98 \%$. High rotating speed can enhance the ozone gas-liquid mass transfer, thus resulting in a high $\eta_{\text {DMP }}$. Lin and Liu [13] also noted that an increase of $N_{\mathrm{r}}$ for a $\mathrm{HG}-\mathrm{OZ}$ process increases the decolorization of RB19 because the centrifugal force increases the interfacial area while decreases the resistance of ozone mass transfer via decreasing the thickness of liquid film and size of droplets. The results of Fig. 5 further showed that as $N_{\mathrm{r}}$ increases higher than $1200 \mathrm{rpm}$, the value of $\eta_{\text {DMP }}$ only increases slightly, indicating the minimiza-

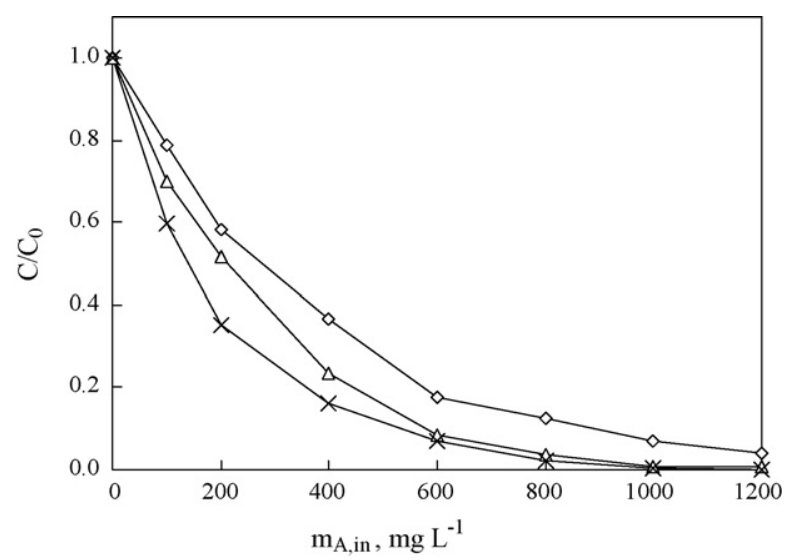

Fig. 6. $C / C_{0}$ vs. $m_{\mathrm{A} \text { in }}$ during ozonation of DMP in HGRPB. $C_{\mathrm{DMPO}}\left(\right.$ or $\left.C_{0}\right)=100 \mathrm{mg} \mathrm{L}^{-1}$, $Q_{\mathrm{G}}=1 \mathrm{~L} \mathrm{~min}^{-1}, Q_{\mathrm{LR}}=462 \mathrm{~mL} \mathrm{~m}^{-1}$, mass of Dash $220 \mathrm{~N}\left(m_{\mathrm{S}}\right)=220 \mathrm{~g}$, power of UV lamp as indicated in specification $=16 \mathrm{~W}, V_{\mathrm{L}}=1 \mathrm{~L}, N_{\mathrm{r}}=1200 \mathrm{rpm}, C_{\mathrm{AG}, \mathrm{in}}=20 \mathrm{mg} \mathrm{L}^{-1}$, $T=25^{\circ} \mathrm{C} .(\diamond)$ : HG-OZ; $(\Delta)$ : HG catalytic ozonation (HG-Pt-OZ); $(\times)$ : HG-UV-Pt-OZ. 


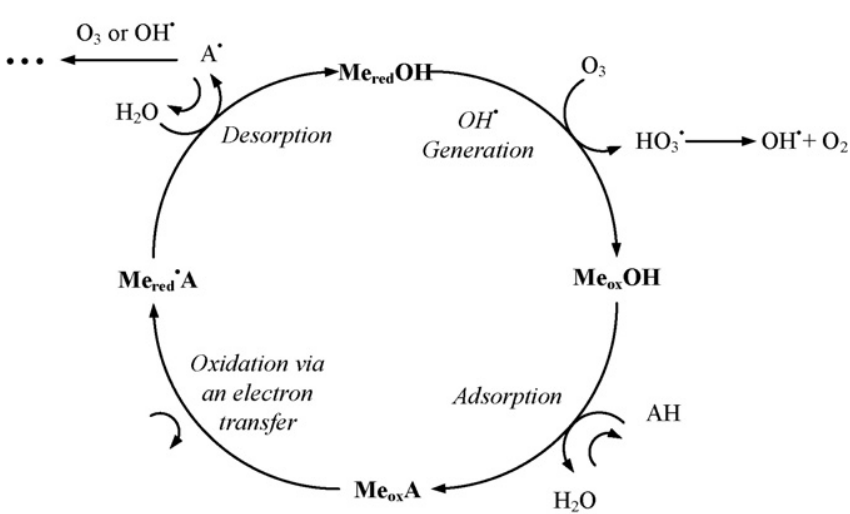

Fig. 7. Scheme illustrating the possible mechanism for ozonation process in the presence of metal-support (metal oxide) catalyst (based on). Me: metal oxide; $\mathrm{AH}$ : organics; ox: oxidation state; red: reduction state [2].

tion of mass transfer resistance. As mentioned previously in Section 3.1, a higher $N_{\mathrm{r}}$ results in a shorter HRT, implying that the time for ozone gas-liquid mass transfer becomes shorter. Although a high $N_{\mathrm{r}}$ can decrease the liquid-film thickness and droplet size to improve the ozone gas-liquid mass transfer rate, however, the short contact time decreases the amount of ozone transferred.

\subsection{Decomposition of DMP via catalytic ozonation}

Fig. 6 presents the decomposition of DMP with and without $\mathrm{Pt} / \gamma-\mathrm{Al}_{2} \mathrm{O}_{3}$ (Dash 220N) during the ozonation in HGRPB. For the case without catalyst, glass beads were used. The value of $\eta_{\text {DMP }}$ for HG-Pt-OZ process reaches $92 \%$ at $m_{\mathrm{A}, \text { in }}=600 \mathrm{mg} \mathrm{L}^{-1}$ (in $30 \mathrm{~min}$ ). The decomposition of DMP is nearly completed at $m_{\mathrm{A}, \mathrm{in}}=1200 \mathrm{mg} \mathrm{L}^{-1}$ (in $60 \mathrm{~min}$ ). A comparison with $\mathrm{HG}-\mathrm{OZ}$ indicates that DMP is decomposed rapidly because Dash $220 \mathrm{~N}$ promotes the dissolved $\mathrm{O}_{3}$ to form highly reactive $\mathrm{OH}^{\bullet}$ radicals. The Pt on the $\mathrm{Al}_{2} \mathrm{O}_{3}$ surface is effective for the decomposition of $\mathrm{O}_{3}$ in gaseous as well as aqueous phase $[18,19]$. The mechanism of the heterogeneous catalytic ozonation in water is shown in Fig. 7 which was explained by Legube and Vel Leitner [4]. Based on the mechanism, the Pt on the Dash 220N surface assists the generation of $\mathrm{OH}^{\bullet}$ radicals. The organic molecules (DMP and intermediates) are adsorbed on the Dash $220 \mathrm{~N}$ surface and oxidized via an electron-transfer reaction. Then the organic radical species are desorbed from the Dash $220 \mathrm{~N}$ and oxidized by $\mathrm{OH}^{\bullet}$ radical or $\mathrm{O}_{3}$.

Combination of HG-Pt-OZ with UV irradiation (HG-UV-Pt-OZ) can further enhance the decomposition of DMP. As shown in

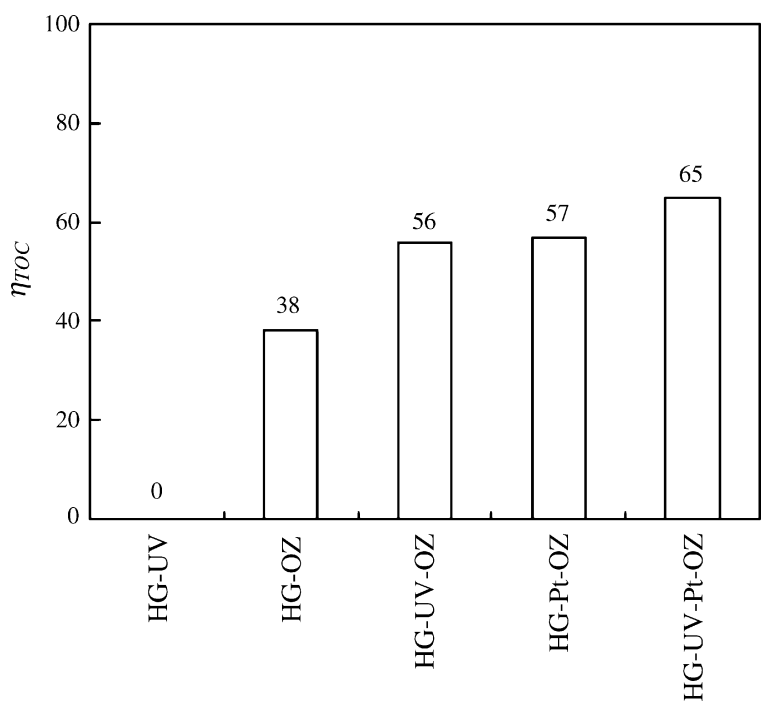

Fig. 8. Mineralization extents ( $\eta_{\mathrm{TOC}}$ ) of different $\mathrm{HG}$ processes. $C_{0}, Q_{\mathrm{G}}, m_{\mathrm{S}}, C_{\mathrm{AG}, \mathrm{in}}, \mathrm{UV}$, $V_{\mathrm{L}}, N_{\mathrm{r}}, T$ : as specified in Fig. 3 . Reaction time $=1 \mathrm{~h}$.

Fig. 6, after $10 \mathrm{~min}$ oxidation $\left(m_{\mathrm{A}, \mathrm{in}}=200 \mathrm{mg} \mathrm{L}^{-1}\right), \eta_{\mathrm{DMP}}$ of $\mathrm{HG}$ UV-Pt-OZ is $65 \%$, while that of HG-Pt-OZ without UV irradiation is $48 \%$. The value $\eta_{\text {DMP }}$ of $\mathrm{HG}-\mathrm{UV}-\mathrm{Pt}-\mathrm{OZ}$ and $\mathrm{HG}-\mathrm{Pt}-\mathrm{OZ}$ at $30 \mathrm{~min}$ $\left(m_{\mathrm{A}, \mathrm{in}}=600 \mathrm{mg} \mathrm{L}^{-1}\right)$ are $94 \%$ and $92 \%$. Both of these two catalytic ozonation processes (with $\mathrm{Pt} / \gamma-\mathrm{Al}_{2} \mathrm{O}_{3}$ or UV radiation) can completely decompose the DMP at $50 \mathrm{~min}\left(m_{\mathrm{A}, \text { in }}=1000 \mathrm{mg} \mathrm{L}^{-1}\right)$.

\subsection{Decomposition of TOC via various Higee processes}

Fig. 8 compares the values of $\eta_{\text {TOC }}$ of the HG related processes. After $1 \mathrm{~h}$ reaction, the HG-UV-OZ and HG-Pt-OZ have about the same decomposition efficiency of TOC ( $\left.\eta_{\mathrm{TOC}}\right)$ of $56 \%$ and $57 \%$, respectively. The result showed that both the UV irradiation and $\mathrm{Pt}$ catalyst can enhance the decomposition of dissolved ozone to form $\mathrm{OH}^{\bullet}$ radicals, assisting the decomposition of TOC. Although ozone was fed and transferred in the HGRPB, the organics in solution were oxidized in HGRPB as well as in photolysis reactor with residual ozone. The transferred ozone is adsorbed on the Dash $220 \mathrm{~N}$ surface and forms $\mathrm{OH}^{\bullet}$ radical to react with organics during the course of catalytic ozonation. The radicals in turn enhance the decomposition reactions of DMP and intermediates.

To further promote the decomposition ability of organic in the HG-UV-OZ and HG-Pt-OZ processes, the UV irradiation is combined with $\mathrm{Pt} / \gamma-\mathrm{Al}_{2} \mathrm{O}_{3}$ catalyst in $\mathrm{HG}-\mathrm{OZ}$ forming a novel HG-UV-Pt-OZ

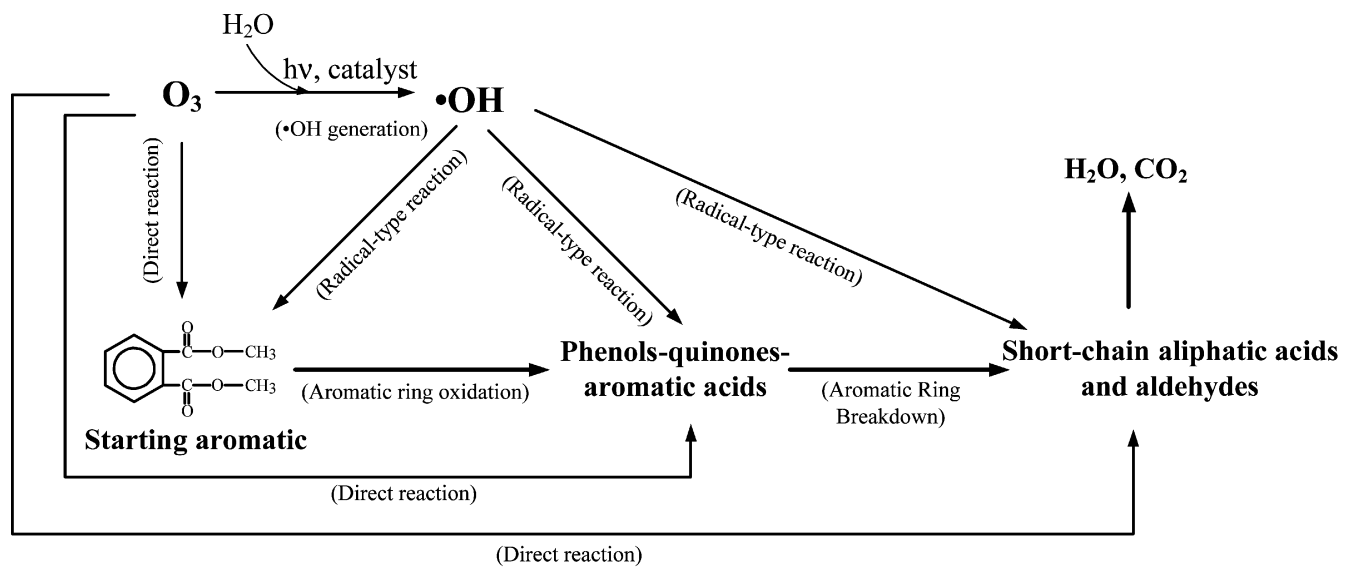

Fig. 9. Simplified scheme illustrating the possible mechanism for the ozonation of DMP with UV and catalyst. 
process. Experiment result showed that, under the same ozone dosage, the HG-UV-Pt-OZ process has the highest $\eta_{\text {TOC }}$ of $68 \%$, comparing with other processes examined in this study.

A simplified scheme of the decomposition pathways of DMP for the catalytic ozonation with UV is shown in Fig. 9. Both the DMP and intermediates are attacked by $\mathrm{O}_{3}$ and $\mathrm{OH}^{\bullet}$ radical. The initial attack of oxidants on DMP during ozonation is via the electrophilic addition to form aromatic acids. Then the aromatic rings are broken down by $\mathrm{O}_{3}$ and $\mathrm{OH}^{\bullet}$ radical to form short-chain organic acids such as oxalic acid, glyoxalic acid and formic acid. These short-chain organic acids are further decomposed to $\mathrm{CO}_{2}$ and $\mathrm{H}_{2} \mathrm{O}$ eventually.

\section{Conclusions}

The decomposition of DMP via HG-OZ, HG-UV-OZ, HG-Pt-OZ and HG-UV-Pt-OZ is investigated in this paper. Several conclusions can be drawn as follows.

(1) Packing Pt $/ \gamma-\mathrm{Al}_{2} \mathrm{O}_{3}$ catalyst (Dash $220 \mathrm{~N}$ ) in $\mathrm{HG}-\mathrm{OZ}$ process can effectively enhance the decomposition of DMP under the experimental conditions of this study. The $\eta_{\text {TOC }}$ of DMP increases from $38 \%$ of $\mathrm{HG}-\mathrm{OZ}$ to $57 \%$ of $\mathrm{HG}-\mathrm{Pt}-\mathrm{OZ}$ because of the formation of $\mathrm{OH}^{\bullet}$ radicals.

(2) The decomposition rate of DMP is dependent on the rotating speed $N_{\mathrm{r}}$ of packing bed. The thickness of liquid film and droplet size decrease with highly centrifugal force. As $N_{\mathrm{r}}$ is higher than $1200 \mathrm{rpm}$, the effect of $N_{\mathrm{r}}$ is greatly reduced.

(3) The use of UV irradiation in HG-Pt-OZ process significantly enhances both the decomposition and mineralization rate of DMP. The HG-UV-OZ process mainly absorbs UV-C $(\lambda=200-280 \mathrm{~nm})$ energy to decompose ozone to form high active radicals. The photolysis of DMP via UV irradiation (HG$\mathrm{UV}$ ) only is negligible.

(4) The combination of UV radiation in HGRPB system can enhance the decomposition of dissolved ozone to form $\mathrm{OH}^{\bullet}$ radicals, assisting the decomposition of TOC.

\section{Acknowledgment}

The authors would like to thank the National Science Council of Taiwan for the financial support of the work (NSC 94-2211-E-267-001).

\section{References}

[1] B.S. Oh, Y.J. Jung, Y.J. Oh, Y.S. Yoo, J.W. Kang, Application of $\mathrm{O}_{3}, \mathrm{UV}$ and $\mathrm{O}_{3} / \mathrm{UV}$ processes to reduce diethyl phthalate and its estrogenic activity, Sci. Total Environ. 367 (2006) 681-693.

[2] L.S. Li, W.P. Zhu, P.Y. Zhang, P. Lu, Q.Y. Zhang, Z.L. Zhang, UV $/ \mathrm{O}_{3}-\mathrm{BAC}$ process for removing organic pollutants in secondary effluents, Desalination 207 (2007) $114-124$.

[3] B. Langlais, D.A. Reckhow, Ozone in Water Treatment: Application and Engineering, Lewis Publishers, Chelsea, Michigan, 1991.

[4] B. Legube, N.K. Vel Leitner, Catalystic ozonation: a promising advanced oxidation technology for water treatment, Catal. Today 53 (1999) 6172.

[5] J. Lin, A. Kawai, T. Nakajima, Effective catalysts for decomposition of aqueous ozone, Appl. Catal. B 39 (2002) 157-165.

[6] C. Ramshaw, R.H. Mallinson, Mass Transfer Process, U.S. Patent 4,283,225 (1981).

[7] C.C. Lin, The Study of Higee, Ph.D. dissertation, Department of Chemical Engineering, National Taiwan University, Taipei, Taiwan, 1999.

[8] Y.H. Chen, C.Y. Chang, W.L. Su, C.C. Chen, C.Y. Chiu, Y.H. Yu, P.C. Chiang, S.I.M. Chiang, Modeling ozone contacting process in a rotating packed bed, Ind. Eng. Chem. Res. 43 (2004) 228-236.

[9] Y.H. Chen, C.Y. Chiu, C.Y. Chang, Y.H. Huang, Y.H. Yu, P.C. Chiang, J.L. Shie, C.S. Chiou, Modeling ozonation process with pollutant in a rotating packed bed, Ind. Eng. Chem. Res. 44 (2005) 21-29.

[10] K. Guo, F. Guo, Y.D. Feng, J.F. Chen, C. Zheng, N.C. Gardner, Synchronous visual and RTD study on liquid flow in rotating packed-bed contactor, Chem. Eng. Sci. 55 (2000) 1699-1706.

[11] Y.S. Chen, The Effect of Viscosity on Mass Transfer in a Rotating Packed Bed, Ph.D. dissertation, Department of Chemical Engineering, National Taiwan University, Taipei, Taiwan, 2004.

[12] Y.H. Chen, Y.H. Huang, R.H. Lin, C.Y. Chang, Production of biodiesel from soybean oil using a rotating packed bed, in: 98th AOCS (American Oil Chemists' Society) Annual Meeting \& Expo, QC, Canada, May 13, 2007.

[13] C.C. Lin, W.T. Liu, Ozone oxidation in a rotating packed bed, J. Chem. Technol. Biotechnol. 78 (2003) 138-141.

[14] Y.H. Chen, C.Y. Chang, W.L. Su, C.Y. Chiu, Y.H. Yu, P.C. Chiang, C.F. Chang, J.L. Shie, C.S. Chiou, S. Chiang, Ozonation of CI Reactive Black 5 using rotating packed bed and stirred tank reactor, J. Chem. Technol. Biotechnol. 80 (2005)6875.

[15] J.L. Shie, C.Y. Chang, J.H. Chen, W.T. Tsai, Y.H. Chen, C.S. Chiou, C.F. Chang, Catalytic oxidation of naphthalene using a Pt/ $/ \mathrm{Al}_{2} \mathrm{O}_{3}$ catalyst, App. Catal. B 58 (2005) 289-297.

[16] L.H. Nowell, J. Hoign, Interaction of iron (II) and other transition metals with aqueous ozone, in: Proceedings of 8th Ozone World Congress, IOA, Zurich, Switzerland, 1988, pp. E80-E95.

[17] G.Y. Peyton, W.H. Glaze, Destruction pollutants in water with ozone in combination with ultraviolet radiation. 3. Photolysis of aqueous ozone, Environ. Sci. Technol. 22 (1988) 761-767.

[18] M.C. Wu, N.A. Kellyb, Clean-air catalyst system for on-road applications. I. Evaluation of potential catalysts, App. Catal. B 18 (1998) 79-91.

[19] K.C. Cho, K.C. Hwang, T. Sano, K. Takeuchi, S. Matsuzawa, Photocatalytic performance of Pt-loaded $\mathrm{TiO}_{2}$ in the decomposition of gaseous ozone, J. Photochem. Photobiol., A 161 (2004) 155-161. 